\title{
The influence of the different techniques of maceration on the aromatic and phenolic profile of the Busuioacă de Bohotin wine
}

\author{
Alexandru C. Tartian ${ }^{1}$, Valeriu V. Cotea ${ }^{1, a}$, Marius Niculaua ${ }^{2}$, Cătălin-Ioan Zamfir ${ }^{1}$, Cintia Lucia Colibaba ${ }^{1}$, \\ and Ana-Maria Moroşanu ${ }^{1}$ \\ ${ }^{1}$ Faculty of Horticulture, University of Agricultural Studies and Veterinary Medicine Iasi, Romania \\ ${ }^{2}$ Research Centre for Oenology, Romanian Academy - Iasi Branch, Romamia
}

\begin{abstract}
The main objective of the present study is to evaluate the influence of the maceration techniques on the volatile and phenolic compounds content of the wines obtained from an autochthonous aromatic variety from Romania. For this study, a pink biotype of the Busuioacă de Bohotin variety from the Huşi vineyard was used. The wine samples were obtained by applying five types of maceration: Classic maceration (V1; S1), Thermo-maceration (V2; S2), Microwave maceration (V3; S3), Ultrasound maceration (V4; S4) and Cryomaceration (V5; S5). The results of the aromatic profile of the wine samples obtained from Busuioacă de Bohotin variety, indicated that the wine samples obtained through cryo-maceration and classic maceration contained a large variety of volatile compounds, namely: alcohols (1-propanol; 2-methyl-1-propanol, 3-methyl-1-butanol, 1-hexanol, phenethyl alcohol e.g.), esters (ethyl octanoate; ethyl caprylate; ethyl lactate; ethyl benzoate; ethyl palmitate e.g.) terpenoid compounds ( $\alpha$-terpineol, linalool, hotrienol, citronellol, nerol, geraniol) and so an. Among alcohols, phenethyl alcohol, which is responsible for floral aroma of roses and is typical for the Busuioacă de Bohotin wine, was found in large quantities in wine samples V1 (4.3 mmol/L) and S5 $(5.53 \mathrm{mmol} / \mathrm{L})$. Terpene compounds and their oxides were identified with elevated levels for linalool (cis- and trans-) and also nerol- as well as linalool-oxide. Analysing the phenolic compounds, it was observed that the total polyphenol index and Folin-Ciocâlteu index expressed higher values for the wine samples V1 and V3. Concerning the total anthocyanins and tannins content, the wine samples obtained had low amounts of this compounds.
\end{abstract}

\section{Introduction}

The volatile and phenolic compounds of wines depends by various factors such as grape variety, terroir, vintage and applied technological process. Among winemaking techniques, maceration plays a primordial roll for the extraction of aromatic and phenolic compounds in wines.

Maceration is responsible for all the specific characteristics of sight, smell and taste where the volatile compounds (primary aromas and aroma precursors) and phenolic compounds (anthocyanins and tannins) are extracted from skins, seeds and sometimes from stems of the grape [1].

This technological operation implies the contact between the juice and the solid parts of the grapes for a specific time. In the evolution process of maceration, four processes of physical-chemical nature are distinguished: the extraction and dissolution of different substances, the diffusion of the substances extracted, refitting the substances extracted on certain molecules from the medium and modification or even the destruction of the substances extracted [2].

Maceration process is influenced by numerous factors such as temperature, duration, alcohol content, $\mathrm{SO}_{2}$ where the extraction of the volatile and phenolic compounds varies according to variety, maturation conditions and other factors. Consequently, the maceration should be

a e-mail: vvcotea@yahoo.com modulated and fractioned according to the grape variety and quality and also to the style of wine desired.

With the evolution of the technology various methods were developed that are available to the winemaker to adjust extraction levels during maceration. These are based on the destruction of the cells' walls favouring the dissolution of chemical compounds of interests [1].

Thermo-vinification or thermo-maceration is a method of maceration known for a long time and implies hightemperature extraction prior to fermentation. Various techniques of thermo-maceration were developed on the basis of evolution of the industrial technologies. The extraction principle consists in heating the whole grapes or the crushed and destemmed grapes to high temperatures $\left(65-80^{\circ} \mathrm{C}\right)$, promoting the diffusion of phenolics from the skins, especially anthocyanins.

For the extraction process of the phenolic and volatile compounds from the grape, non-conventional techniques can also be used such as microwave and ultrasound maceration, that recognised as outstanding energy sources to promote extraction, cutting down extraction times and increasing yields as well as often the quality of extract [3].

Microwave extraction principle consists in the absorption of the energy by the water present within the cells thus, promoting internal superheating [4]. The heated water evaporates and generates tremendous pressure on the cell wall, resulting thereby the disruption of the cell wall and migration of the active constituents [5]. 
Microwave maceration is based on heating the pomace by exposing it to microwave radiation in the electromagnetic spectrum. This method has been highlighted to be efficient in terms of rate and effectiveness of polyphenolic extraction from the grapes [6-11].

The use of ultrasounds technology in food engineering has become very popular. The continuous interests in this is due to numerous advantages given by this method (reduces the process time, saves energy and improves shelf life and quality of food products) and the large applications offered such as: peeling, disruption of cell, the production of enzymes without bacterial cells, extraction, acceleration of microbial fermentation, mixing, homogenization, extraction etc. [11-13].

In the oenology department, various studies analyse this method, for: extraction of oil and polyphenols from grape seeds [14], effects on cold maceration and fermentation [15], extraction of anthocyanins [16], extraction of antioxidant bioactive compounds from winery wastes and by-products [17], extraction of volatile compounds [18], acceleration of wine's aging [19].

The extraction application of ultrasounds is based on cavitation phenomenon which consists in the formation of cavities when the sound wave passes through an elastic medium, inducing a longitudinal displacement of particles and acting like a piston, therefore producing the disruption of the cell tissue.

Cryo-maceration is another technique of maceration which involves lowering the temperature of the pomace or the whole grapes to at least $-18^{\circ} \mathrm{C}$ and maintaining this temperature for a specific period of time. Temperature is achieved by using a freezer or cryogenic gases $\left(\mathrm{CO}_{2}\right.$ or $\mathrm{N}_{2}$ ). During this process, intracellular water from the grape is frozen and the ice crystals formed cause the rupture of the cell tissue and migration of the chemical compounds of interest. (aroma precursors, anthocyanins, tannins) [20,21]. Generally, the wines obtained by cold temperature gain a more aromatic complexity [1], cryomaceration favouring the extraction of varietal aromas such as monoterpenes while the phenolic compounds are limited [22,23].

Busuioacă de Bohotin variety originates either from ancient Greece, as a close relative of Tămâioasă românească, another aromatic Romanian grape variety, either from France, from the very similar Muscat violet de Frontignan [24].

The wines obtained from Busuioacă de Bohotin variety have a flavour reminiscent of the scent of roses, basil, coriander, wild strawberries where the colour can range from pink with violet hues to pale orange (salmon, onion skin).

The aim of the present study is to evaluate the influence of different techniques of maceration on the aromatic and phenolic profile of the wines obtained from Busuioacă de Bohotin grape variety.

\section{Materials and methods}

\subsection{Grape samples}

Busuioacă de Bohotin grape variety has two biotypes which differ mainly by the colour of the grapes' skin: dark violet and pink. The pink biotype presents a low pigmentation degree, being commonly used in combination with the other.

For this reason, a less known biotype of this variety was used in this study in order to explore the aromatic and phenolic profile of the wines obtained under different conditions of maceration.

The experiment was done over the course of two years, during which ten wine samples were obtained from the pink biotype of Busuioacă de Bohotin variety. The pink biotype grapes were harvested from $\mathrm{Hu}$ ?i vineyard at technological maturity in the years $2014\left(\mathrm{~A}_{0}\right)$ and 2015 $\left(A_{1}\right)$. The main physico-chemical characteristics of the grapes are presented in Table 1 below.

Table 1. The main physic-chemical parameters of the grapes.

\begin{tabular}{|l|c|c|}
\hline Sample & $\begin{array}{c}\text { Total acidity } \\
\text { g/L tartaric acid }\end{array}$ & Sugars g/L \\
\hline $\mathrm{A}_{0}$ & 5.7 & 248.7 \\
\hline $\mathrm{A}_{1}$ & 5.41 & 230 \\
\hline
\end{tabular}

\subsection{Wine samples}

The wines samples analysed in this study were obtained by applying five maceration techniques:

\subsubsection{Classical maceration $\left(V_{1}, S_{1}\right)$ :}

the grapes were crushed, destemmed and the resulting pomace was introduced in maceration vessels.

\subsubsection{Thermo-maceration $\left(V_{2}, S_{2}\right)$ :}

the juice resulted from the crushing and destemming operations was pumped into a metallic recipient and heated to a temperature of $70^{\circ} \mathrm{C}$ for 15 minutes. After reaching this temperature, the juice was transferred into a maceration vessel and mixed with the remainder pomace.

\subsubsection{Microwave maceration $\left(V_{3}, S_{3}\right)$ :}

the obtained pomace was microwaved at $750 \mathrm{~W}$ for 15 minutes and was manually homogenized at 3 minutes intervals. The end temperature of the pomace was $60^{\circ} \mathrm{C}$.

\subsubsection{Ultrasound maceration $\left(V_{4}, S_{4}\right)$ :}

it was performed in an ultrasonic bath where the pomace was sonicated at a frequency of $35 \mathrm{KHz}$ for 30 minutes.

\subsubsection{Cryo-maceration $\left(V_{5}, S_{5}\right)$ :}

the whole grapes were frozen slowly to a temperature of $-20^{\circ} \mathrm{C}$ for 24 hours in order to promote the formation of large ice crystals and thus favouring the break of the skin grape tissue. The frozen grapes were manually destemmed and crushed.

The remainder maceration time after all the above mentioned processes was of seven days for all the variants. The temperature of the pomace was maintained at $20^{\circ} \mathrm{C}$ and yeast - Fermactive Rouge Primeur ${ }^{\circledR}$ and pectolytic enzyme was added - Zymovarietal Aroma $G^{\circledR}$.

After 7 days of maceration the pomace was pressed using a hydraulic press and the alcoholic fermentation ended in glass vessels. After alcoholic fermentation, the 
wines were racked, filtered, $\mathrm{SO}_{2}$ was added $(1 \mathrm{ml} / \mathrm{L})$ and bottled.

The two groups of obtained wine samples were registered as follows: $\mathbf{V}$ - for the wine samples obtained in 2014 and $\mathbf{S}$ - the wine samples obtained in 2015. The the wine samples were analysed from a physico-chemical point of view according to the O.I.V. methods and the following parameters were determined: volatile acidity (a), total acidity - (b), alcohol content - (c), total dry extract $-(\mathbf{d}), \mathrm{pH}-(\mathbf{e})$ and conductivity - (f) in Table 2.

Table 2. Main physico-chemical parameters of the wines obtained through different maceration techniques.

\begin{tabular}{|c|l|l|l|l|l|l|}
\hline Sample & $\mathbf{a}$ & $\mathbf{b}$ & $\mathbf{c}$ & $\mathbf{d}$ & $\mathbf{e}$ & $\mathbf{f}$ \\
\hline $\mathbf{V}_{\mathbf{1}}$ & 0.35 & 5.84 & 14.31 & 22.9 & 3.80 & 2.37 \\
\hline $\mathbf{V}_{\mathbf{2}}$ & 0.33 & 5.94 & 14.01 & 23.5 & 3.78 & 2.45 \\
\hline $\mathbf{V}_{\mathbf{3}}$ & 0.37 & 5.84 & 14.41 & 25.3 & 3.84 & 2.40 \\
\hline $\mathbf{V}_{\mathbf{4}}$ & 0.31 & 5.45 & 13.91 & 21.6 & 3.77 & 2.28 \\
\hline $\mathbf{V}_{\mathbf{5}}$ & 0.33 & 5.40 & 14.23 & 21.9 & 3.78 & 2.30 \\
\hline $\mathbf{S}_{\mathbf{1}}$ & 0.37 & 5.87 & 15.20 & 27.1 & 3.34 & 1509 \\
\hline $\mathbf{S}_{\mathbf{2}}$ & 0.37 & 5.82 & 15.10 & 26.8 & 3.34 & 1450 \\
\hline $\mathbf{S}_{\mathbf{3}}$ & 0.62 & 6.01 & 15.24 & 26.8 & 3.30 & 1476 \\
\hline $\mathbf{S}_{\mathbf{4}}$ & 0.37 & 4.79 & 14.78 & 25 & 3.35 & 1513 \\
\hline $\mathbf{S}_{\mathbf{5}}$ & 0.31 & 4.37 & 14.55 & 22.7 & 3.31 & 1493 \\
\hline
\end{tabular}

Volatile acidity g/L - (a), total acidity g/L- (b), alcohol content \%vol.- (c), total dry extract $\mathrm{g} / \mathrm{L}-(\mathbf{d}), \mathrm{pH}-(\mathbf{e})$ and conductivity $\mu \mathrm{S} / \mathrm{cm}-(\mathbf{f})$.

\subsection{Gas-chromatographic analysis of volatile compounds}

In order to conduct the determination of the volatiles compounds, all samples were analysed using a gas chromatograph with a mass spectrometer system (Shimadzu HS 20trap-GC 2010plus-MS8040TQ). The system uses helium as carrier gas and the adsorption material in trap as stationary phase is a resin of 2,6-diphenylene oxide (TENAX).

$6 \mathrm{~mL}$ of wine were added to mixture of $0.8 \mathrm{~g}$ from the following salts: $\mathrm{Na} \mathrm{Cl}, \mathrm{Na}_{2} \mathrm{SO}_{4}$ and $\mathrm{KH}_{2} \mathrm{PO}_{4}$ in a vial for analysis of vapours (headspace fraction) using the method of salting out. All samples were heated to $70^{\circ} \mathrm{C}$ and shacken at $25 \mathrm{rpm}$ for 5 minutes. The vials were pressurised to $60 \mathrm{KPa}$ with helium to remove condense. The volatile fraction was transferred into a Tenax trap at $-10^{\circ} \mathrm{C}$ by a transfer line at $150^{\circ} \mathrm{C}$. Before injection for half a minute the trap is dry purged and then the volatiles are transferred at $280^{\circ} \mathrm{C}$ with a split of $1 / 50$ in to the analytic column.

The separation column used is a Phenomenex ${ }^{\circledR}$ ZB WAXplus $60 \mathrm{~m} \times 0.25 \mathrm{~mm}$ ID $\times 0.15 \mu \mathrm{m}$ which is contained in a temperature - controlled oven. Temperature program for separation is: the total injection time 2 minute, temperature remains constant for 3 minutes at $82^{\circ} \mathrm{C}$, then starts increasing with $3^{\circ} \mathrm{C} / \mathrm{min}$. up to $135^{\circ} \mathrm{C}$, maintains for 1 minute, then $7.5^{\circ} \mathrm{C} / \mathrm{min}$. up to $160^{\circ} \mathrm{C}$, maintains for 1 minute and finally increases with $27^{\circ} \mathrm{C} / \mathrm{min}$. to $240^{\circ} \mathrm{C}$, remaining constant for 8 minutes (total temperature program 37 minutes). Separation is carried-out at a constant linear velocity of $35 \mathrm{~cm} / \mathrm{s}$ (column flow $1.5 \mathrm{~mL} / \mathrm{min}$ ).

The 8040 triple quadrupole is utilised in Q3 (third quadrupole) scan mode from $30-400 \mathrm{Da}$ at $0.1 \mathrm{~s}$ event time
$(5000 \mathrm{scan} / \mathrm{sec})$. The ion source interface is maintained at $230^{\circ} \mathrm{C}$ and source at $200^{\circ} \mathrm{C}$.

The results are processed qualitatively comparing them to different MS databases available: NIST 14, Wiley 10, FFNSC and SZTERP. For the quantitative results, all samples are processed by internal standard method relative to 4-methyl-pentan-2-ol.

\subsection{Folin- Ciocalteu index and total polyphenols index}

Folin-Ciocâlteu Index (FCI) describes the phenolic compounds with reducing proprieties and is based on the oxidation in a basic medium of the phenolic compounds from wine by the Folin-Ciocâlteu reagent.

The blue coloration produced has a maximum absorption around $750 \mathrm{~nm}$ (visible light) and it is proportional to the total amount of phenolic compounds (OIV-MA-AS2-10).

Total Polyphenols Index (PTI) or D280 index expresses the total content of the phenolic compounds of wine (anthocyanins, tannins, flavones etc.) and consists on the strong absorption of the ultraviolet light by the benzenic cores characteristic for the phenolic compounds, with a maximum absorption at $280 \mathrm{~nm}$.

\subsection{Total content of anthocyanins by $\mathrm{pH}$ variation method}

This method is based on the existence of a balance between the coloured and uncoloured forms of the anthocyanins in acidic medium. The absorption differences obtained between the two $\mathrm{pH}$ solutions ( 0.6 and 3.5$)$ at a wavelength of $520 \mathrm{~nm}$ is proportional to the content of anthocyanins.

\subsection{Tannins by MCP (methyl cellulose precipitable) method}

The assay is based on the interactions between the tannins and a polymer, resulting in the formation of insoluble polymer tannin complexes, which precipitates.

The polymer used is methyl cellulose and the values of tannin content of the wines analysed are obtained by subtracting the absorbance values at $280 \mathrm{~nm}$ (A280) of the both solutions, with and without precipitation.

The FCI and D280 indexes, total anthocyanins and tannins were determined using a Analytic Jena S 200 spectrophotometer.

\subsection{Evaluation of chromatic characteristics}

In order to evaluate the chromatic features of the analysed samples a spectrophotometer Analytic Jena S was used.

CIE La*b* is the most complete colour model used to describe the colours of the visible spectrum because it allows the specification of the largest number of shades of colour that a person could perceive with $a^{*} b^{*}$ values. Therefore, the range of colours based on this model is described as the widest range of reproducible colours of the visible spectrum.

Basically, the CIE Lab 76 colour or space system is based on a sequential or continuous Cartesian representation of three orthogonal axes: $L, a$ and $b . L$ represents the clarity, $a$ represents the green/red shades of colour and $b$ represents the blue/yellow shades of colour. 


\section{Results and discussions}

Analysing the values of the main physico-chemical parameters (Table 2) of the samples obtained through different technique of maceration were highlighted some differences.

In terms of total acidity (b), it was revealed that the samples obtained by ultrasound maceration and cryomaceration expressed the lowest values regardless of the year they were produced. The most pronounced differences were observed in 2015, where the minimum value of total acidity was registered in the cryo-maceration wine sample ( $4.37 \mathrm{~g} / \mathrm{L}$ tartaric acid) followed closely by the ultrasound sample $(4.79 \mathrm{~g} / \mathrm{L})$. This situation can be caused by the favouring of the precipitation of tartaric acid determined by the used techniques of maceration.

$\mathrm{pH}$ (e) or the true acidity plays an important role in the wines, enhancing their microbiological and physicochemical stability. Regarding the wine samples obtained in the two years of experiment, the $\mathrm{pH}$ values did not vary greatly indifferent of the technique of maceration applied or the total acidity values. Thus, the $\mathrm{pH}$ values varied between 3.77 and 3.80 for 2014 wine samples and between 3.30 and 3.35 in 2015. This situation can be due to the tampon effect of the wine and the presence of highly ionized acids.

In terms of alcohol content (c), the use of different techniques of maceration didn't have a big influence on the wine samples obtained.

Thereby, in 2014 the alcohol content of the wines samples varied between a minimum of $13.91 \%$ for the ultrasound maceration sample (V4) and a maximum of $14.41 \%$ for the microwave maceration (V3) sample while in 2015 this parameter varied between $14.55 \%$ (S5cryo-maceration sample) and $15.24 \%$ (S3 -microwave maceration). If the vintage of the wine samples is taken into account, the wine samples obtained in 2015 had bigger values of alcoholic concentration in contrast with 2014 wine samples and it is mainly because of the higher values of the sugars of the grapes harvested in 2015.

The volatile acidity (a) of the wine is considered to be a highly important physico-chemical parameter that describes the general quality of the wine and it is given mainly by the presence of the acetic acid. In the case of the wine samples obtained in this study, this parameter ranged in general between $0.31(\mathrm{~g} / \mathrm{L}$ acetic acid) and $0.37(\mathrm{~g} / \mathrm{L})$. The only difference was identified in 2015 for the microwave maceration sample with a value of $0.62(\mathrm{~g} / \mathrm{L})$ and can be caused probably by the contact with a larger amount of oxygen during vinification.

In order to highlight the influence of the technique of maceration upon the degree of extraction of the non-volatile organic and inorganic substances, the total dry extract (d) was analysed. Thus, the most extractive methods of maceration have been revealed to be microwave maceration sample (V3) with $25.3 \mathrm{~g} / \mathrm{L}$ in 2014 and classic maceration sample (S1) with $27.1 \mathrm{~g} / \mathrm{L}$ in 2015.

At the opposite pole, the cryo-maceration $(22.7 \mathrm{~g} / \mathrm{L})$ and ultrasound maceration samples $(21.6 \mathrm{~g} / \mathrm{L})$ obtained the lowest values for total dry extract.

The conductivity (f) of a wine depends on the concentration and the mobility of the ionic species (anionic and cationic) present in the solution such as: acids, bases, salts, nitrogen compounds (proteins, enzymes, amino
Table 3. Folin Ciocâlteu Index, PTI Index, Tannins and Anthocyanins.

\begin{tabular}{|l|l|l|c|c|}
\hline Sample & FCI & PTI & $\begin{array}{c}\text { Anthocyanins } \\
\text { (mg/L) }\end{array}$ & $\begin{array}{c}\text { Tannins } \\
\text { (epicatechin } \mathbf{~ m g ~ / L ) ~}\end{array}$ \\
\hline V1 & 15.79 & 12.25 & 2.84 & n.d. \\
\hline V2 & 8.95 & 7.83 & 1.37 & n.d. \\
\hline V3 & 12.85 & 7.80 & 1.12 & n.d. \\
\hline V4 & 4.98 & 3.89 & 1.12 & n.d. \\
\hline V5 & 10.21 & 8.46 & 0.57 & n.d. \\
\hline S1 & 25.29 & 21.38 & n.d. & 104.85 \\
\hline S2 & 27.77 & 21.79 & n.d. & 63.61 \\
\hline S3 & 32.53 & 24.28 & n.d. & 76.66 \\
\hline S4 & 22.15 & 17.44 & n.d. & 78.55 \\
\hline S5 & 22.36 & 17.97 & n.d. & 42 \\
\hline
\end{tabular}

n.d- Non-detectable.

acids) etc. Concerning the wine samples studied, in 2014, the values of the conductivity are above $2 \mu \mathrm{S} / \mathrm{cm}$ while the samples from 2015 expressed lower values, been situated between 1450 and $1509 \mu \mathrm{S} / \mathrm{cm}$.

This variation of the wine samples conductivity is depending only on the year of production and is not influenced by the technique of maceration applied, being in direct correlation with the values of $\mathrm{pH}$. Analysing the values presented in the Table 3 it can be observed that are some differences regarding the phenolic compounds of wine samples obtained by different techniques of maceration.

Thereby, in the year 2014 the wine samples obtained by ultrasound maceration contain the lowest amounts of phenolic compounds with values of 3.89 for PTI and 4.98 for FCI while the highest values where identified at classic maceration technique with 12.25 (PTI) and 15.79 (FCI). In 2015, the most extractive technique of maceration in terms of phenolic compounds indexes has been pointed out to be microwave maceration with values of 24.28 for PTI and 32.53 for FCI while at the opposite pole stands the cryomaceration (17.97 PTI and 22.36 FCI) followed closely by the ultrasound maceration sample.

Comparing the wine samples obtained in this two years of experiment it was highlighted clearly that the wine samples obtained in 2015 contained more phenolic compounds than the 2014 samples. This fact can be explained by the higher alcohol content of the 2015 wine samples and his strong effect on the extraction of the phenolic compounds from the grapes during maceration.

Concerning the anthocyanins and tannins content of the wine samples analysed were observed the presence in lower amounts and even the absence of this two compounds. Thus, regarding the anthocyanins content, were identified only in 2014 wine samples with values that ranged between a maximum of $2.84 \mathrm{mg} / \mathrm{L}$ (V1) and a minimum of $0.57 \mathrm{mg} / \mathrm{L}$ (V5). The small amounts of anthocyanins identified in this wine samples can be primarily due to the low pigmentation level of the pink biotype of Busuioacă de Bohotin variety and secondly because of the irreversible reactions of anthocyanins by oxidation, poly-condensation with tannins or even by combination with amino acids and other nitrate compounds.

Concerning the tannin content, they were identified only in the 2015 wine samples with values that varied between $42 \mathrm{mg} / \mathrm{L}$ epicatechin (S5) and $104.85 \mathrm{mg} / \mathrm{L}$ (S1). 
Table 4. Chromatic parameters of the analysed samples.

\begin{tabular}{|l|c|c|c|}
\hline \multirow{2}{*}{ Samples } & \multirow{2}{*}{ Clarity } & \multicolumn{2}{|c|}{ Chromaticity } \\
\cline { 3 - 4 } & & $\mathbf{a}^{*}$ & $\mathbf{b}^{*}$ \\
& & & \\
\hline V1 & 96.2 & 2.69 & 11.21 \\
\hline V2 & 95.6 & 2.47 & 11.85 \\
\hline V3 & 95.9 & 2.16 & 10.70 \\
\hline V4 & 95.7 & 0.74 & 7.42 \\
\hline V5 & 97.4 & 0.54 & 6.78 \\
\hline S1 & 93.6 & 3.96 & 17.57 \\
\hline S2 & 93.6 & 3.72 & 18.27 \\
\hline S3 & 92.7 & 4.88 & 19.74 \\
\hline S4 & 96.0 & 2.02 & 10.27 \\
\hline S5 & 95.1 & 2.57 & 13.44 \\
\hline
\end{tabular}

The presence of the tannins just in the 2015 wine samples can be explained by the influence of the high alcoholic concentration during the maceration of these samples, thus promoting a better extraction of this compounds from the seeds and skins of grapes.

In the case of 2014 wine samples, the absence of the tannins can be due to a possible hydrolysis of the tannins and the formation of a larger amounts of tannins with low polymerization degree that can react with other molecules such as proteins, amino acids and therefore resulting the precipitation of these compounds.

Observing the main chromatic parameters (Table 4) it can be stated that wine samples with high levels of clarity (L) were obtained, where the yellow shades (b) prevailed the red shades (a). These results are primarily due to the low content of anthocyanins and tannins.

Regarding the influence of the technique of maceration upon the chromatic characteristics of the wine samples, the ultrasound and cryo-maceration methods had an impact. Thus, the wines samples obtained by these techniques had the lowest values of red $(+a)$ and yellow $(+b)$, also presenting the highest values of clarity (L).

For identifying the volatile compounds from the wine samples, the GC-MS method was used and the results were expressed quantitatively in $\mathrm{mmol} / \mathrm{L}$ according to the standard solution 4-methyl-pentan-2-ol.

Alcohols are formed during alcoholic fermentation process whether from sugars or from amino acids by the yeast metabolism, contributing to the wine's aromatic complexity. Alcohols like 1-propanol, 2-methyl1-propanol (isobutyl alcohol) and 3-methyl-1-butanol (isoamyl alcohol) are the most representative fusel alcohols which are found in the largest quantities in wines and imprints in general a fermented, alcoholic and ethereal odour.

Referring to the wine samples from this study, these compounds were found in higher quantities in the samples where were applied microwave maceration (2014) and cryo-maceration (2015) techniques (Table 5).

Another significant part of the alcohols they also have the higher alcohols with six carbon atoms which derive from grape polyunsaturated fatty acids (linoleic acids) and give the herbaceous smell of wines and they could hypothetically contribute to judge wine origin and affiliation [26]. From this group of compounds, they were identified 1-hexanol, cis-3-hexen-1-ol, cis and trans-2-hexen-1-ol where 1-hexanol was the only compound that was identified in the both years of the wine samples studied and in the largest amounts.

Regarding to the influence of the technique of maceration upon this compound it was observed that the highest quantity of 1-hexanol was identified in the cryo-macerated wines samples $(3.06 \mathrm{mmol} / \mathrm{L}$ in 2014 and $6.8 \mathrm{mmol} / \mathrm{L}$ in 2015).

Of the benzene-derived higher alcohols, phenyl ethyl alcohol is the most important and is also the only fusel alcohol described with positive terms such as sweet, perfumed, and dry rose [26]. In this study, this compound was identified in the largest amounts in the wine samples where were applied classic maceration ( $4.30 \mathrm{mmol} /$ L-2014) and cryo-maceration (5.53 mmol/L - 2015).

Benzyl alcohol is another higher alcohol compound which has a floral, rose odour and it was found in large quantities in the classic-maceration $(0.20 \mathrm{mmol} / \mathrm{L}-2014)$ and in cryo-maceration $(0.26 \mathrm{mmol} /$ L - 2015) wine samples.

Esters occur in wines as a major volatile compound mainly from the enzymic esterification during fermentation and generally contribute to the fruity wine odours. Among the esters identified in this study (Table 6), ethyl caprylate, ethyl caprate, ethyl laurate, ethyl myristate and ethyl palmitate were found in higher concentrations. These compounds have very pleasant odours of wax and honey and the concentration of these esters tend to decrease over time as wine ages due to spontaneous hydrolysis.

In the wines samples analysed were identified bigger amounts of ethyl caprylate $(16.84 \mathrm{mmol} / \mathrm{L})$ at thermo-maceration sample (S2), higher concentrations of ethyl myristate $(1.97 \mathrm{mmol} / \mathrm{L})$ and ethyl palmitate $(4.32 \mathrm{mmol} / \mathrm{L})$ for the cryo-maceration sample (S5) while the classic maceration sample (S1) expressed high quantities of ethyl caprate $(4.88 \mathrm{mmol} / \mathrm{L})$ and ethyl laurate ( $2.71 \mathrm{mmol} / \mathrm{L})$.

Ethyl lactate is an ester responsible for the buttery, creamy odours with hints of fruit and coconut which was found in large amounts in the cryo-maceration wine samples (2.95 mmol/L-2014; $6.18 \mathrm{mmol} / \mathrm{L}-2015)$.

Esters like 2-phenylethyl acetate responsible for the apple and honey like aromas, diethyl succinate who gives fruity, apple odours and ethyl benzoate responsible for the minty odours were found in higher concentration in wine samples where cryo-maceration and classic maceration were applied. The cryo-maceration wine samples illustrated also the presence in larger amounts of the ethyl 3-hydroxybutanoate who contributes to the marshmallow-like aromas. It was observed that the wine samples obtained by cryo-maceration and classicmaceration had bigger amounts of esters, thus, it can be stated that the techniques of maceration applied in this study had an important influence on the amounts of this compounds formed during maceration.

It was also highlighted that the wine samples obtained in 2015 had bigger concentration of esters comparing with the wine samples obtained in 2014.

The terpenoid compounds (Table 7) are known as the substances that are present in grapes (skins mostly) and are partially responsible for the typical varietal character of the grape cultivar (especially for the Muscat varieties) and consequently to the wine produced. 
Table 5. Alcohols identified in the analysed wine samples.

\begin{tabular}{|l|l|l|l|l|l|l|l|l|l|l|}
\hline $\begin{array}{l}\text { Alcohols } \\
\text { (mmol/L) }\end{array}$ & $\mathrm{V} 1$ & $\mathrm{~V} 2$ & $\mathrm{~V} 3$ & $\mathrm{~V} 4$ & $\mathrm{~V} 5$ & $\mathrm{~S} 1$ & $\mathrm{~S} 2$ & $\mathrm{~S} 3$ & $\mathrm{~S} 4$ & $\mathrm{~S} 5$ \\
\hline 1-propanol & 0.54 & 0.43 & 0.58 & 0.49 & 0.52 & 0.87 & 0.99 & 0.77 & 0.003 & 1.36 \\
\hline 2-methyl-1-propanol & 0.01 & 0.67 & 0.69 & 0.64 & 0.63 & 1.04 & 1.03 & 0.73 & 0.002 & 1.41 \\
\hline 3-methyl-1-butanol & 3.89 & 3.39 & 3.58 & 2.51 & 2.51 & 6.17 & 6.83 & 5.27 & 0.021 & 9.50 \\
\hline 1-pentanol & 0.17 & 0.13 & 0.03 & 0.03 & 0.14 & 0.21 & 0.12 & 0.09 & 0.002 & 0.13 \\
\hline 4-methyl-1-pentanol & 0.15 & 0.13 & 0.01 & 0.01 & 0.10 & 0.04 & 0.07 & 0.05 & nd & 0.07 \\
\hline 3-methyl-1-pentanol & 0.16 & 0.26 & 0.03 & 0.03 & 0.15 & 0.11 & 0.11 & 0.09 & 0.002 & 0.19 \\
\hline 1-hexanol & 2.91 & 2.61 & 1.90 & 2.50 & 3.06 & 2.99 & 4.31 & 1.99 & 0.004 & 6.80 \\
\hline cis-3-hexen-1-ol & 0.49 & 0.25 & 0.64 & 0.33 & 0.48 & n.d. & n.d. & n.d. & n.d. & n.d. \\
\hline trans-2-hexen-1-ol & n.d. & n.d. & n.d. & n.d. & 0.05 & 0.03 & n.d. & n.d. & n.d. & 0.04 \\
\hline 1-octen-3-ol & 0.05 & 0.15 & n.d. & n.d. & n.d. & 0.07 & 0.12 & 0.05 & n.d. & 0.13 \\
\hline 1-heptanol & 0.40 & 0.15 & 0.05 & 0.07 & 0.22 & 0.56 & 0.48 & 0.32 & 0.001 & 0.58 \\
\hline 2-ethyl-1-hexanol & 0.09 & 0.06 & 0.02 & 0.02 & 0.08 & 0.07 & 0.05 & 0.05 & n.d. & 0.08 \\
\hline 2,6-dimethyl-4-heptanol & 0.04 & n.d. & 0.02 & n.d. & 0.06 & n.d. & n.d. & n.d. & n.d. & 0.03 \\
\hline 1-octanol & 0.07 & 0.22 & 0.03 & 0.02 & 0.07 & 0.17 & 0.14 & 0.11 & n.d. & 0.19 \\
\hline benzyl alcohol & 0.20 & 0.20 & 0.12 & 0.12 & 0.12 & 0.21 & 0.15 & 0.12 & nd & 0.26 \\
\hline phenethyl alcohol & 4.30 & 1.98 & 2.71 & 2.18 & 2.74 & 3.63 & 3.45 & 2.89 & 0.002 & 5.53 \\
\hline 2,6-dimethyl-3,7-octadiene-2,6-diol & 0.21 & 0.28 & 0.10 & 0.14 & 0.16 & n.d. & n.d. & n.d. & n.d. & n.d. \\
\hline 1-tetradecanol & 0.32 & 0.27 & n.d. & 0.09 & 0.27 & n.d. & n.d. & n.d. & n.d. & n.d. \\
\hline
\end{tabular}

Table 6. Esters identified in the wine samples analysed.

\begin{tabular}{|l|l|l|l|l|l|l|l|l|l|l|}
\hline $\begin{array}{l}\text { Esters (mmol/L) } \\
\text { (mmol/L) }\end{array}$ & V1 & V2 & V3 & V4 & V5 & S1 & S2 & S3 & S4 & S5 \\
\hline ethyl pyruvate & 0.11 & 0.10 & n.d. & 0.02 & 0.12 & n.d. & 0.06 & 0.08 & n.d. & 0.11 \\
\hline ethyl caprylate & 0.17 & n.d. & n.d. & 0.16 & 0.20 & 15.85 & 16.48 & 11.74 & n.d. & 6.84 \\
\hline ethyl lactate & 2.22 & 2.12 & 1.60 & n.d. & 2.95 & 3.51 & 3.87 & 3.24 & n.d. & 6.18 \\
\hline ethyl 3-hidroxybutanoate & 0.03 & 0.17 & 0.01 & n.d. & 0.22 & n.d. & 0.04 & n.d. & n.d. & 0.01 \\
\hline diethyl malonate & n.d. & n.d. & n.d. & n.d. & 0.02 & n.d. & 0.03 & n.d. & n.d. & n.d. \\
\hline ethyl caprate & 0.06 & n.d. & n.d. & 0.05 & 0.06 & 4.88 & 4.19 & 2.74 & n.d. & 1.35 \\
\hline ethyl benzoate & 0.29 & 0.33 & 0.14 & 0.14 & 0.15 & 0.19 & 0.18 & 0.12 & n.d. & 0.22 \\
\hline diethyl succinate & 1.21 & 0.75 & 0.90 & 0.79 & 1.12 & 0.58 & 0.61 & 0.38 & n.d. & 1.00 \\
\hline ethyl salicilate & 0.06 & 0.04 & 0.01 & 0.02 & n.d. & 0.03 & 0.04 & n.d. & n.d. & 0.01 \\
\hline 2-phenylethyl acetate & 0.10 & 0.14 & 0.05 & 0.04 & 0.14 & 0.03 & 0.03 & 0.03 & n.d. & 0.13 \\
\hline ethyl laurate & 0.12 & 0.09 & 0.07 & 0.05 & 0.05 & 2.71 & 2.51 & 1.88 & n.d. & 1.09 \\
\hline isopropyl myristate & 0.28 & 0.00 & 0.04 & 0.06 & n.d. & 0.05 & 0.01 & 0.05 & n.d. & 0.06 \\
\hline ethyl myristate & 0.28 & 0.38 & 0.28 & 0.12 & 0.36 & 1.64 & 1.21 & 1.11 & n.d. & 1.97 \\
\hline ethyl heptanoate & n.d. & n.d. & n.d. & 0.03 & n.d. & 0.20 & 0.15 & 0.12 & n.d. & 0.03 \\
\hline ethyl cinnamate & 0.26 & 0.14 & 0.06 & 0.16 & n.d. & n.d. & n.d. & 0.03 & n.d. & n.d. \\
\hline ethyl pentadecanoate & 0.21 & 0.24 & 0.12 & 0.00 & 0.25 & 0.32 & 0.14 & 0.27 & trace & 0.55 \\
\hline ethyl palmitate & 1.09 & 1.04 & 0.61 & 0.63 & 1.11 & 3.09 & 3.07 & 2.46 & n.d. & 4.32 \\
\hline ethyl 9-hexadecenoate & 0.34 & 0.42 & 0.33 & 0.41 & 0.68 & 0.16 & 0.10 & 0.20 & trace & 0.44 \\
\hline (Z)-ethyl pentadec-9-enoate & n.d. & n.d. & 0.08 & 0.00 & 0.20 & n.d. & n.d. & 0.09 & n.d. & 0.12 \\
\hline ethyl stearate & 0.63 & n.d. & 0.31 & 0.14 & 0.47 & 0.35 & 0.18 & 0.15 & n.d. & 0.27 \\
\hline ethyl oleate & n.d. & 0.25 & 0.17 & n.d. & 0.48 & 0.04 & 0.48 & nd & n.d. & n.d. \\
\hline
\end{tabular}

In the studied wine samples, 21 terpenoid compounds were identified such as: simple hydrocarbons (limonene, $\alpha$-terpinene), alcohols (linalool, hotrienol, $\alpha$-terpineol, $\alpha$ -citronellol, citronellol, nerol, geraniol, prenol), oxides of alcohols (cis-and trans-linalool oxide in pyranic and furanic form, nerol oxide, rose oxide), acids (geranic and neric acids), and even esters ( $\alpha$-terpinyl acetate).

Among the most odoriferous monoterpenes are alcohols such as linalool, nerol, geraniol which have a have a floral odour of rose, $\alpha$-terpineol responsible for the lily of the valley odour, citronellol (citronella) and hotrienol (linden) were found in the highest amounts in the wine samples obtained through cryo-maceration regardless of the vintage. Also, for this odorants compounds, the lowest values were identified in the wine samples obtained by ultrasound maceration and microwave maceration which seems to have negative effects on the terpenoid compounds.

In the wine samples a large variety of terpenoids oxides such as oxides of linalool, nerol, geraniol and traces of rose oxide was also found.

These oxides of monoterpenes compounds are due to the oxidation reactions that occur prior to fermentation, being triggered during extraction of the juice and maceration [27].

Linalool oxides which are responsible for the camphorous and mineral odour and nerol oxides (green and herbaceous) have a high perception threshold compared to the unoxidized forms of the terpenes and consequently they have little olfactory impact on 
Table 7. Terpenoid compounds identified in the wine samples.

\begin{tabular}{|c|c|c|c|c|c|c|c|c|c|c|}
\hline $\begin{array}{l}\text { Terpenoids compounds } \\
(\mathrm{mmol} / \mathrm{L})\end{array}$ & V1 & V2 & V3 & V4 & V5 & S1 & S2 & S3 & S4 & S5 \\
\hline limonene dioxide & 0.07 & n.d. & n.d. & n.d. & n.d. & n.d. & n.d. & n.d. & n.d. & n.d. \\
\hline nerol oxide & 0.07 & n.d. & 0.01 & 0.01 & 0.13 & 0.07 & 0.11 & 0.04 & n.d. & 0.04 \\
\hline trans-linalool oxide (furanoid) & n.d. & n.d. & n.d. & 0.10 & 0.32 & 0.12 & 0.10 & 0.07 & n.d. & 0.20 \\
\hline$\alpha$-terpinene & n.d. & n.d. & n.d. & n.d. & 0.07 & 0.08 & n.d. & 0.60 & n.d. & n.d. \\
\hline cis linalool oxide & 0.23 & 0.31 & 0.23 & n.d. & n.d. & n.d. & 0.04 & 0.04 & trace & n.d. \\
\hline trans linalool oxide & 0.14 & nd & 0.08 & 0.06 & 0.15 & n.d. & n.d. & n.d. & n.d. & n.d. \\
\hline linalool & 1.48 & 0.81 & 0.74 & 0.90 & 1.14 & 2.17 & 2.44 & 1.71 & 0.002 & 2.24 \\
\hline hotrienol & 0.47 & 0.34 & 0.35 & 0.25 & 0.54 & 0.13 & 0.21 & 0.13 & 0.001 & 0.14 \\
\hline$\alpha$-terpineol & 0.62 & 0.56 & 0.63 & 0.59 & 1.15 & 0.40 & 0.43 & 0.36 & 0.002 & 0.51 \\
\hline linalool oxide-pyranoyd & 0.29 & 0.21 & 0.23 & 0.14 & 0.14 & 0.07 & 0.07 & 0.04 & n.d. & 0.09 \\
\hline$\alpha$-citronellol & 0.08 & n.d. & n.d. & n.d. & n.d. & n.d. & n.d. & n.d. & n.d. & n.d. \\
\hline citronellol & 0.53 & 0.32 & 0.14 & 0.43 & 1.00 & 0.59 & 0.50 & 0.39 & 0.0007 & 0.82 \\
\hline nerol & 0.38 & 0.31 & 0.16 & 0.34 & 0.54 & 0.41 & 0.36 & 0.23 & 0.0002 & 0.46 \\
\hline geraniol & 0.33 & 0.23 & 0.27 & 0.28 & 0.37 & 0.20 & 0.20 & 0.12 & n.d. & 0.25 \\
\hline trans-geranylgeraniol & n.d. & n.d. & n.d. & n.d. & 0.18 & n.d. & n.d. & n.d. & n.d. & 0.13 \\
\hline prenol & n.d. & 0.10 & n.d. & n.d. & 0.06 & trace & n.d. & n.d. & n.d. & n.d. \\
\hline rose oxide & n.d. & n.d. & n.d. & n.d. & n.d. & 0.02 & n.d. & n.d. & n.d. & n.d. \\
\hline$\alpha$-terpinyl acetate & n.d. & n.d. & n.d. & n.d. & n.d. & 0.04 & n.d. & 0.01 & n.d. & 0.03 \\
\hline$\gamma$ - isogeraniol & n.d. & n.d. & n.d. & n.d. & n.d. & n.d. & n.d. & 0.01 & n.d. & n.d. \\
\hline neric acid & 0.97 & n.d. & 0.40 & n.d. & 0.36 & n.d. & n.d. & n.d. & trace & n.d. \\
\hline geranic acid & n.d. & n.d. & n.d. & n.d. & n.d. & 0.16 & 0.14 & 0.09 & n.d. & n.d. \\
\hline
\end{tabular}

wines. These oxides seem to occur in lower quantities compared with their homologues. Thus, the linalool oxides express values which are ranging between a minimum of $0.04 \mathrm{mmol} / \mathrm{L}$ and a maximum of $0.31 \mathrm{mmol} / \mathrm{L}$ (cislinalool).

It was also observed the presence of the oxides of nerol and linalool in the wine samples obtained in 2014.

Geranic acid is a compound resulting from the oxidation of geraniol and it was identified in small amounts in the 2015 wine samples.

Rose oxide is a more odoriferous compound and it is partly responsible for the floral aroma of Gerwurztraminer wines [27]. Referring to the wine samples analysed, only a trace of this compound $(0.02 \mathrm{mmol} / \mathrm{L})$ was found, in one sample ( $\mathrm{S} 1$ - classic maceration).

$\alpha$-terpinyl acetate is the only ester who can be classified as a terpenoid compound, imprinting herbaceous and spicy odours and it was found in small amounts (0.01 mmol/L - S3; $0.04 \mathrm{mmol} / \mathrm{L}$ - S1).

$\alpha$-terpinene is a terpenoid compound who was identified in very large amounts only in the microwave wine sample $(0.6 \mathrm{mmol} / \mathrm{L})$ and it is responsible for the resin-like odours.

\section{Conclusions}

The detailed physico-chemical analyses of the wine samples obtained by different techniques of maceration revealed the following aspects:

In terms of the main physico-chemical parameters, it was highlighted that the wine samples obtained by microwave and classic maceration expressed higher values of total dry extract while the cryo-maceration and ultrasound maceration were the least extractive techniques.

The pink biotype of the Busuioacă de Bohotin variety had a low content of anthocyanins and tannins, being samples where these compounds could not be detected by the assay applied. The wine samples obtained by cryo-maceration and ultrasound maceration contained the lowest amounts of phenolic compounds, being and the less coloured wine samples produced.

Concerning the volatile profile, it was highlighted that the wines obtained by cryo-maceration technique were the most abundant in compounds such as phenethyl alcohol, nerol, geraniol, hotrienol, citronelol and $\alpha$-terpineol which have a floral aroma reminiscent of rose essence and gives the typical varietal character of Busuioacă de Bohotin wines.

With respect to the influence of the vintage upon the phenolic and aromatic profile of the wines it was revealed that the 2015 wine samples had in generally higher amounts of phenolic and volatile compounds.

\section{References}

[1] P. Ribéreau-Gayon, D. Dubourdieu, B. Donèche, A. Lonvaud, "Handbook of Enology Volume I - The Microbiology of Wine and Vinifications", $2^{\text {nd }}$ Edition, 347 (2006)

[2] V.D. Cotea, -"Tratat de Oenologie" - Vinificaţia şi biochimia vinului I, 479 (1985)

[3] A. Casazza, B. Aliakbarian, S. Mantegna, G. Cravotto, P. Perego, Journal of Food Eng. 100, 50-55 (2010)

[4] L. Wang, C.L. Weller, Trends Food Sci. Technol. 17, 300-12 (2006)

[5] V. Mandal, Y. Mohan, S. Hemalatha, Microwave Assisted Extraction - An Innovative and Promising Extraction Tool for Medicinal Plant Research, Pharmacognosy Reviews 1(1), (2007)

[6] S.A. Bittar, S. Périno-Issartier, O. Dangles, F. Chemat, An innovative grape juice enriched in polyphenols by microwave-assisted extraction, Food Chem. 141(3), 3268-3272 (2013)

[7] A. Liazid, M. Palma, J. Brigui, C.G. Barroso, Investigation on phenolic compounds stability during 
microwave-assisted extraction, Journal of Chromatography A 1140, 29-34 (2007)

[8] L. Anna, Carew, M.A. Sparrow, D.C. Curtin, C. Dugald, Close, G.R. Dambergs, Microwave Maceration of Pinot Noir Grape Must: Sanitation and Extraction Effects and Wine Phenolics Outcomes, Food Bio.Techno. 1 7, 954-963 (2014)

[9] A. Liazid, R.F. Guerrero, E. Cantos, M. Palma, C.G. Barroso, Microwave assisted extraction of anthocyanins from grape skins, Food Chem. 124, 1238-1243 (2011)

[10] Ş. Tudose-Sandu-Ville, V.V. Cotea, C. Colibaba, B. Nechita, M. Niculaua, M. Codreanu, Phenolic Compounds in Merlot Wines Obtained Through Different Technologies in Iaşi Vineyard, Cercetări Agronomice în Moldova (XLV 4), 152 (2012)

[11] A.C. Vollmer, E.C. Everbach, Halpern, M. Kwakye, Bacterial stress responses tol-megahertz pulsed ultrasound in the presence of microbubbles, Applied Env. Microb. 64, 3927-3931 (1998)

[12] G.D. Betts, A. Williams, R.M. Oakley, Ultrasonic standing waves, inactivation of foodborne microorganism using power ultrasound, Encyclopedia of Food Microb., 2202-2208 (1999)

[13] A. Demirdoven, T. Baysal, The use of ultrasound and combined technologies in food preservation, Food Reviews Intern. 25, 1-11 (2009)

[14] C.D. Porto, E. Porretto, D. Decorti, Comparison of ultrasound-assisted extraction with conventional extraction methods of oil and polyphenols from grape (Vitis vinifera L.) seeds, Ultra.Sonochemistry 20, 1076-1080 (2013)

[15] N.E. Darra, H.N. Rajha, M.A. Ducasse, M.F. Turk, N. Grimi, R.G. Maroun, N. Louka, E. Vorobie, Effect of pulsed electric field treatment during cold maceration and alcoholic fermentation on major red wine qualitative and quantitative parameters, Food Chem. 213, 352-360 (2006)

[16] S.Y. Leong, D.J. Burritt, O. Indrawati, Evaluation of the anthocyanin release and health-promoting properties of Pinot Noir grape juices after pulsed electric fields, Food Chem. 196, 833-841 (2016)

[17] F.J. Barba, Z. Zhu, M. Koubaa, A.S. Sant'Ana, V. Orlien, Trends in Green alternative methods for the extraction of antioxidant bioactive compounds from winery wastes and by-products: A review, Food Scien. \&Techn. 49, 96-109 (2016)

[18] S. Cabredo-Pinillos, T. Cedron-Fernandez, M. Gonzalez-Briongos, L. Puente-Pascual, C. SaenzBarrio, Ultrasound-assisted extraction of volatile compounds from wine samples: Optimisation of the method, Talanta 69, 1123-1129 (2006)

[19] A.C. Chang, F.C. Chen, The application of $20 \mathrm{kHz}$ ultrasonic waves to accelerate the aging of different wines, Food Chem. 79, 501-506 (2002)

[20] M. Couasnon, Une nuvelle technique: la maceration pre-fermentaire à froid-Extraction a la nieve carbonique, part I. Revue des oenologues et des techniques vitivinicoles et oenologiques 92, 26-30 (1999)

[21] A. Parenti, P. Spugnoli, L. Calamai, S. Ferrari, C. Gori, Effects of cold maceration on red wine quality from Tuscan Sangiovese grape, European Food Res. and Techn. 218, 360-366 (2004)

[22] V. Gerbi, G. Zeppa, C. Manara, J.L. Minati, Experience in cold maceration with Muscat grapes, L'Enotecnico 27, 57-66 (1991)

[23] S. Radeka, S. Herjavec, Peruri, I. Luki, B. Sladonja, Effect of different maceration treatments on free and bound varietal aroma compounds in wine of Vitis vinifera L.cv. Malvazija istarska bijela, Food Technol. Biotechnol. 46, 86-92 (2008)

[24] L.C. Colibaba, V.V. Cotea, F.G. Lacureanu, S. Tudose-Sandu-Ville, L. Rotaru, M. Niculaua, C.E. Luchian, Studies of phenolic and aromatic profile of Busuioacă de Bohotin wines, BIO Web of Conf. 5 (2015)

[25] J.M. Oliveira, M. Faria, S. Filomena, F. Barros, M.A Isabel, C6-alcohols as varietal markers for assessment of wine origin, Analytica Chim. Acta 563, 300-309 (2006)

[26] R.F. Simpson, Some important aroma components of white wine, Food Technol. Aust. 31, 516-522 (1979)

[27] P. Ribéreau-Gayon, Y. Glories, A. Maujean, D. Dubourdieu, "Handbook of Enology Volume II - The Chemistry of Wine. Stabilization and Treatments", $2^{\text {nd }}$ Edition, 9 (2006) 